\title{
ÍNDICES DE DESENVOLVIMENTO RURAL: COMPARAÇÃO ENTRE OS MUNICÍPIOS DO VALE DO RIO CUIABÁ E OS DEMAIS MUNICÍPIOS DE MATO GROSSO: 2000 E 2008
}

Meiresângela Miranda Muniz* Benedito Dias Pereira**

RESUMO: A partir dos anos mais recentes, a base econômica dos municípios do Vale do Rio Cuiabá e dos outros municípios do Estado de Mato Grosso se movimentam em trilhas convergentes, produzindo os bens que mais se destacam na agropecuária do Estado: a soja, o algodão, o milho e os bovinos. Embora haja essa confluência, as economias dos municípios que compõem o Vale do Rio Cuiabá ainda exibem diferenças em relação às economias dos demais municípios mato-grossenses. Nesse contexto, com adoção do método de análise multivariada, pesquisa-se sobre os contrastes do desenvolvimento rural entre esses dois conjuntos de municípios. Os principais resultados revelam que as economias dos municípios que fazem parte do Vale, de modo geral, em comparação com grande parte dos outros municípios mato-grossenses, vêm apresentado índices mais reduzidos de desenvolvimento rural.

PALAVRAS-CHAVE: Crescimento; Desenvolvimento; Desenvolvimento rural.

\section{INDEXES OF RURAL DEVELOPMENT: COMPARING MUNICIPALITIES OF THE CUIABÁ RIVER VALLEY AND OTHER MUNICIPALITIES IN THE STATE OF MATO GROSSO, BRAZIL: 2000 AND 2008}

\begin{abstract}
It has recently been estimated that the economic basis of the municipalities of the Cuiabá River basin and that of the other municipalities of the state of Mato Grosso, Brazil, are on convergent tracks. They produce goods, such as soybean, cotton, corn and cattle, which underscore the state's agricultural and cattle industry. In spite of the convergence, the economy of these municipalities is different from that of the other municipalities of the state. Employing the multi-variegated analysis method, contrasts in rural development between these two sets of municipalities are discussed. Results reveal that the economy of the municipalities of the Cuiabá River

\footnotetext{
Mestre em Economia pela Universidade Federal de Mato Grosso e Técnica do DIEESE em Cuiabá (MT), Brasil.

** Mestre e Doutor em Economia Agrícola pela Universidade Federal de Pernambuco (UFPE), Brasil.

E-mail: bdp@terra.com.br
} 
Valley, as a rule, presents decreasing rural development when compared to others municipalities of the state.

KEY WORDS: Growth; Development; Rural development.

\section{INTRODUÇÃO}

Ao longo dos últimos anos, Mato Grosso vem experimentando diversas alterações em sua base econômica, impulsionadas, sobretudo, pelo acelerado aumento do seu PIB. A origem dessa base se formou com suporte na pecuária extensiva e na produção de outros bens de subsistência. Atualmente, ela está se especializando na produção de bens agropastoris de exportação, com preponderância da soja, mas, também, com expressiva produção de algodão, milho e de bovinos.

Em paralelo a essas transformações se constatam várias mudanças na hierarquização das economias dos municípios, com realce para aquelas que apresentam maior crescimento e desenvolvimento econômico, e que, portanto, mais contribuem para posicionar a economia do Estado como uma das que se destacam no país em termos de taxa de crescimento dos seus agregados macroeconômicos e como uma das líderes na exportação de produtos agropecuários.

Esses resultados estimulam reflexões voltadas para a comparação de indicadores entre as economias de determinados conjuntos de municípios de Mato Grosso. Um desses conjuntos formam o Vale do Rio Cuiabáa . Diante disso, para pertinente contraste entre eles, realizam-se estimativas de indicadores de desenvolvimento rural para dois conjuntos de economias: as que formam o Vale do Rio de Cuiabá e as relativas à economia do Estado como um todo.

Desse modo, como o desenvolvimento se constitui em categoria que potencialmente pode proporcionar melhoria de bem-estar para a maioria das regiões e atores nele envolvidos, as discussões com centralidade no desenvolvimento rural

3 O termo Vale do Rio Cuiabá surgiu através da Lei Complementar n 359, de 27 de maio de 2009. De acordo com essa Lei, os municípios que compõem essa nova unidade de organização regional são: Cuiabá, Várzea Grande, Nossa Senhora do Livramento, Santo Antônio de Leverger, Acorizal, Barão do Melgaço, Chapada dos Guimarães, Jangada, Nobres, Nova Brasilândia, Planalto da Serra, Poconé e Rosário Oeste. Disponível em: $<$ http://www.iomat.mt.gov.br/> . Acesso em: 05 set. 2013. 
estimulam múltiplas reflexões acerca dos efeitos desse processo sobre os agentes e os espaços que lhes são afetos. Essas consequências podem estar se revestindo de determinadas especificidades na economia de Mato Grosso, visto que alguns caracteres que nela se destacam lhe conformam razoável singularidade. Dentre essas características pode-se citar: estrutura fundiária com acentuada concentração, número restrito de produtos, como a soja, algodão, milho e poucos outros, além da presença de grandes e modernas organizações, que se inserem no ambiente mundial globalizado de maneira extremamente competitiva.

É natural que, como entendem muitos dos estudiosos desse e de temas afins, as abordagens sobre desenvolvimento trazem consigo diversos procedimentos que requerem cautela metodológica e simplificações analíticas. Para Kageyama (2004, p. 1): "O desenvolvimento - econômico, social, cultural, político - é um conceito complexo e só pode ser definido por meio de simplificações, que incluem decomposição de alguns dos seus aspectos e aproximação por algumas formas de medida”. Uma dessas simplificações pode ser representada pelas estimativas de Índices de Desenvolvimento.

Ademais, podendo ser entendido como conciliação entre desenvolvimento exógeno (definido e imposto por forças externas à região) e endógeno (centrado no desenvolvimento local), o desenvolvimento rural pode ser considerado: "Uma combinação de forças internas e externas à região, em que os atores das regiões rurais estão envolvidos simultaneamente em um complexo de redes locais e redes externas que podem variar significativamente entre regiões", como descreve Kageyama (20014, p. 3) ao resumir a contribuição de Terluin (2003) sobre o conceito de desenvolvimento rural.

Nesse contexto, com centralidade na categoria de desenvolvimento rural, este trabalho estima o Índice de Desenvolvimento Rural (IDR), concebido como ferramenta para aferir o desenvolvimento rural das economias de dois conjuntos de municípios do Estado de Mato Grosso. Sobre esses dois conjuntos, rearfimando-se: Um é constituído pelos municípios que integram o Vale do Rio Cuiabá, enquanto o outro é formado por todos os municípios do Estado. Entende-se IDR como indicador que abriga diversos aspectos (social, econômico e ambiental) das economias investigadas. Vários pesquisadores nacionais já estimaram o IDR em vários contextos 
regionais, como Kageyma (2004), Melo e Parré (2007) e Stege e Parré (2011).

Nesse quadro, embora com convergência com as dos demais municípios de Mato Grosso, a base produtiva dos municípios que compõem o Vale do Rio Cuiabá apresenta formação histórica mais remota e características que lhe são específicas, todavia, não vivencia o mesmo dinamismo das economias dos muncípios mais jovens. Nesse cenário, formula-se a seguinte pergunta: Entre 2000 e 2008 diminui a participação relativa do índice de desenvolvimento rural das economias alusivas ao Vale do Rio Cuiabá no índice afim da economia de Mato Grosso? Pressupóe-se que, em supremacia, os municípios que fazem parte do Vale do Rio Cuiabá apresentam índices de desenvolvimento rural menores em comparação a muitos outros muncípios de Mato Grosso. As estimativas que se realizam para esse contraste serão efetuadas com dados de 2000 e 2008.

Além desta Introdução, este Artigo contém mais três partes, ou seja, sequencialmente, abordam-se: o material e o método, a análise e a discussão dos resultados e os comentários finais.

\section{MATERIAL E MÉTODO}

Mato Grosso possui 141 municípios, sendo que 13 formam o Vale do Rio Cuiabá. As estatísticas usadas são de natureza secundária, compiladas na base de dados da Secretaria do Estado de Planejamento e Coordenação Geral (SEPLAN/MT) e do Instituto Brasileiro de Geografia e Estatística (IBGE). Com dados de 2000 e 2008, para se aferir o Índice Bruto de Desenvolvimento (IBD), que antecede a estimativa do Índice de Desenvolvimento Rural (IDR), adota-se o método de Análise Fatorial, um dos membros da Análise Multivariada, que se complementa com Componentes Principais, Análise de Cluster (análise de conglomerados) e Análise Discriminante. As estimativas foram realizadas com o uso do software SPSS versão 15.

Por oportuno, de acordo com Corrar, Paulo e Dias Filho (2007, p. 02), a Análise Multivariada se constitui em um "conjuto de métodos estatísticos que torna possível a análise simultânea de medidas múltiplas para cada indivíduo", com a finalidade de se otimizar a compreensão de grandes números de variáveis, na maioria das vezes, interligadas. 


\subsection{A ANÁLISE FATORIAL}

De acordo com Bezerra (2007, p. 74): "A Análise Fatorial tem como um de seus principais objetivos tentar descrever um conjunto de variáveis originais através da criação de um número menor de dimensões ou fatores”. Ou ainda, como sintetiza Mingotti (2005, p. 99): "A análise fatorial tem como objetivo principal descrever a variabilidade original do vetor aleatório $\mathrm{X}$, em termos de um número menor $\mathrm{m}$ de variáveis aleatórias, chamadas de fatores comuns e que estão relacionadas com o vetor original X através de um modelo linear".

A primeira etapa da análise fatorial considera a matriz das correlações entre os indicadores originais. Nessa etapa são obtidas as informações que verificam a adequação da amostra ao procedimento estatístico, com recorrência ao teste KMO (critério de Kayser-Meyer-Olkin).

Indicando a dimensão da variância das variáveis explanadas por fatores comuns, para que um modelo de análise fatorial possa ser apropriadamente ajustado aos dados é necessário que a matriz da correlação inversa das variáveis originais seja próxima da matriz diagonal. O teste KMO avalia esse grau de aderência (MINGOTTI, 2005 , p. 137). Com vistas ao incremento do rigor analítico, além do teste KMO, a análise da adequacidade dos dados também pode ser efetuada através de outro teste: o de esfericidade de Bartlett. De acordo com Mingoti (2005, p. 138) esse teste se fundamenta da seguinte forma:

O ajuste de um modelo de análise fatorial aos dados pressupõe que as variáveis-resposta sejam correlacionadas entre si. Desse modo, quando as variáveis são provenientes de uma distribuição normal p-variada, é possível fazer o teste de hipótese para verificar se a matriz de correlação populacional é próxima ou não da matriz identidade.

$\mathrm{Na}$ etapa imediatamente seguinte define-se o número de fatores que condensam o conjunto original de dados, ordenados de forma decrescente. O primeiro fator está associado à raiz característica mais elevada, explicativa da maior variância dos dados. Após essas etapas os fatores obtidos são submetidos a uma rotação com o objetivo de transformá-los em grandezas interdependentes. Através desse procedimento, os indicadores que exibem correlação mais expressiva entre si se inserem no 
mesmo fator, idealmente se aproximando do valor máximo (número um).

Estimados a partir da multiplicação entre o valor da variável e o coeficiente do escore fatorial correspondente, em seguida são calculados os escores fatoriais. Assim, o grau de desenvolvimento dos municípios é hierarquizado de acordo com os escores fatoriais de cada observação (MELO; PARRÉ, 2007).

Após a realização dessas etapas, por fim, calcula-se o Índice Bruto de Desenvolvimento (IBD) por meio da estimação da média de fatores pertencentes a cada observação, ponderada pela variância. Uma vez estimado o IBD obtém-se o Índice de Desenvolvimento Rural (IDR) para cada município a partir de interpolação, elaborando-se a classificação dos municípios quanto ao seu grau de desenvolvimento rural com adoção de critério a ser oportunamente detalhado.

\subsection{DESCRIÇÕES DAS VARIÁVEIS}

As variáveis que serão utilizadas, medidas por intermédio de proporções, estão descritas a seguir, denominadas de $\mathrm{X}_{1}$ a $\mathrm{X}_{22}$ : $\mathrm{X}_{1}$ : Número de Bovinos/Número de Estabelecimentos com Bovinos; $\mathrm{X}_{2}$ : Número de Suínos/Número de Bovinos; $\mathrm{X}_{3}$ : Número de Aves/Número de Bovinos; $\mathrm{X}_{4}$ : Área Plantada com Soja/Área Plantada Total; $\mathrm{X}_{5}$ : Área Plantada com Algodão/Área Plantada Total; $\mathrm{X}_{6}$ : Área Plantada com Abacaxi/Área Plantada Total; $\mathrm{X}_{7}$ : Área Plantada com Arroz/Área Plantada Total; $\mathrm{X}_{8}$ : Área Plantada com Feijão/Área Plantada Total; $\mathrm{X}_{9}$ : Área Plantada com Mandioca/Área Plantada Total; $\mathrm{X}_{10}$ : Área Plantada com Milho/Área Plantada Total; $\mathrm{X}_{11}$ : Área Plantada com Cana-de-açúcar/Área Plantada Total; $\mathrm{X}_{12 \text { : }}$ Área com Lavouras/Área Total; $\mathrm{X}_{13}$ : Produtividade da Terra na Cultura da Soja (Quantidade Produzida de Soja/Área Plantada com Soja) $\mathrm{X}_{14}$ : Produtividade da Terra na Cultura do Algodão (Quantidade Produzida de Algodão/Área Plantada com Algodão); $\mathrm{X}_{15}$ : Produtividade da Terra na Cultura do Milho (Quantidade Produzida de Milho/Área Plantada com Milho); $\mathrm{X}_{16}$ : Produtividade da Terra na Cultura da Cana-de-açúcar (Quantidade Produzida de Cana-de-açúcar/ Área Plantada com Cana-de-açúcar); $\mathrm{X}_{17}$ : Matrícula Total do Ensino Fundamental/ Número de Professores do Ensino Fundamental; $\mathrm{X}_{18}$ : Matrícula total do Ensino Médio/Número de Professores do Ensino Médio; $\mathrm{X}_{19}$ : Matrícula total de Educação de Jovens e Adultos/Número de Professores do Ensino Médio; $\mathrm{X}_{20}$ : Leitos Hospitalares/ População Total do Município; $\mathrm{X}_{21}$ : Benefícios concedidos pelo INSS/População Total 
do Município; $\mathrm{X}_{22}$ : Área Autorizada de Queimada/Área total.

Essas vinte e duas variáveis foram agrupadas de acordo com a relevância e respectivas contribuições às análises da seguinte maneira: Grupo $1\left(G_{1}\right)$ : Intensidade e Exploração da Terra: $\mathrm{X}_{4}, \mathrm{X}_{5}, \mathrm{X}_{6}, \mathrm{X}_{7}, \mathrm{X}_{8}, \mathrm{X}_{9}, \mathrm{X}_{10}$ e $\mathrm{X}_{11}$; Grupo $2\left(\mathrm{G}_{2}\right)$ : Escala, Pecuarização e Modernização da Pecuária: $X_{1}, X_{2}$ e $X_{3}$; Grupo $3\left(G_{3}\right)$ : Desempenho na Agricultura e Desenvolvimento Econômico: $\mathrm{X}_{12}, \mathrm{X}_{13}, \mathrm{X}_{14}, \mathrm{X}_{15}$ e $\mathrm{X}_{16}$; Grupo $4\left(\mathrm{G}_{4}\right)$ : Educação: $\mathrm{X}_{17}, \mathrm{X}_{18}$ e $\mathrm{X}_{19}$; Grupo $5\left(\mathrm{G}_{5}\right)$ : Saúde e Previdência: $\mathrm{X}_{20}$ e $\mathrm{X}_{21}$; Grupo $6\left(\mathrm{G}_{6}\right)$ : Degradação Ambiental: $\mathrm{X}_{22}$.

\section{RESULTADO E DISCUSSÃO}

Considerando as 22 variáveis, inicialmente calculou-se a matriz das correlações simples entre elas, acompanhada dos valores dos KMO's para análise da adequabilidade dos dados. Os indicadores dos KMO's mostraram resultados insatisfatórios, pois os valores gravitaram em torno de 0,53 e de 0,47 , respectivamente, em 2000 e 2008, como pode ser visto na Tabela 1.

Tabela 1. Indicador de Kaiser-Meyer-Olkin (KMO): 2000 e 2008

\begin{tabular}{llcc}
\hline \multirow{2}{*}{ Indicadores } & \multicolumn{2}{c}{ Ano } \\
\cline { 3 - 4 } \multicolumn{2}{c}{ Medida de adequação de Kaiser-Meyer-Olkin } & 0,53 & 0,47 \\
\hline Prova de esfericidade de Bartlett & Qui-quadrado & 1448,57 & 1598,57 \\
& Graus de Liberdade & 231 & 231 \\
& Nível de Significância & 0,00 & 0,00 \\
\hline
\end{tabular}

Fonte: Resultado da pesquisa, 2012.

Em decorrência desses resultados, as variáveis que exibiram menor correlação com as demais foram excluídas. As variáveis excluídas (7) foram: $\mathrm{X}_{4}$ (Área Plantada com Soja/Área Plantada Total), $X_{5}$ (Área Plantada com Algodão/Área Plantada Total) $\mathrm{X}_{6}$ (Área Plantada com Abacaxi/Área Plantada Total) $\mathrm{X}_{11}$ (Área Plantada com Cana-de-açúcar/Área Plantada Total) $\mathrm{X}_{19}$ (Matrícula total de Educação de Jovens e Adultos/Número de Professores do Ensino Médio) $\mathrm{X}_{20}$ (Leitos Hospitalares/Popula- 
ção Total do Município) e $X_{22}$ (Área Autorizada de Queimada/Área total).

Em seguida, a partir das estimativas geradas pelas 15 variáveis remanescentes verificou-se que os indicadores dos KMO's apresentaram resultados de 0,66 para os dados pertinentes a 2000 e 0,72 para os referentes a 2008. Esses valores são considerados, respectivamente, como "regular" e "bom". O valor máximo desse indicador é um, e o mínimo, zero, conforme pontuam Pereira et al. (2008, p. 05). Por consequência, infere-se que é possível se analisar os indicadores obtidos a partir dessas 15 variáveis, visto que as estimativas resultam confiáveis, rejeitando-se, portanto, a hipótese nula de que a matriz de correlação é uma matriz identidade.

Após essa etapa, as informações das variáveis foram condensadas em cinco fatores selecionados, com raízes características que superam o número um, que em conjunto explicam 68,48\% (2000) e 66,66\% (2008) das variâncias totais, como se nota na Tabela 2:

Tabela 2. Raiz característica, percentual explicado por cada fator e variância acumulada (\%): 2000 e 2008

\begin{tabular}{ccccccc}
\hline & \multicolumn{2}{c}{ Raiz característica } & \multicolumn{2}{c}{$\begin{array}{c}\text { Variância explicada } \\
\text { pelo fator (\%) }\end{array}$} \\
\cline { 2 - 7 } Fator & 2000 & 2008 & 2000 & 2008 & 2000 & 2008 \\
\cline { 2 - 7 } & 3,304 & 4,030 & 22,026 & 26,868 & 22,026 & 26,868 \\
F1 & 3,101 & 1,813 & 20,671 & 12,084 & 42,697 & 38,952 \\
F3 & 1,527 & 1,702 & 10,177 & 11,345 & 52,874 & 50,297 \\
F4 & 1,243 & 1,307 & 8,287 & 8,715 & 61,161 & 59,012 \\
F5 & 1,097 & 1,147 & 7,316 & 7,646 & 68,477 & 66,658 \\
\hline
\end{tabular}

Fonte: Resultado da pesquisa, 2012.

Em sequência, as Tabelas 3 e 4 exibem as cargas fatoriais e as comunalidades dos fatores, sendo consideradas apenas as cargas fatoriais com valores acima de 0,50 , destacadas em negrito. Na Tabela 3, observa-se que praticamente todas as variáveis têm sua variabilidade captada e representada pelos cinco fatores, com exceção da variável $\mathrm{X}_{3}$, cujo valor não se posiciona acima de 0,50 .

Tabela 3. Cargas Fatoriais e Comunalidades: 2000 


\begin{tabular}{ccccccc}
\hline \multirow{2}{*}{ Variáveis } & \multicolumn{5}{c}{ Cargas Fatoriais } & \multirow{2}{*}{$\begin{array}{c}\text { Comunali- } \\
\text { dades }\end{array}$} \\
\cline { 2 - 6 } $\mathrm{X}_{1}$ & $\mathrm{~F} 1$ & $\mathrm{~F} 2$ & $\mathrm{~F} 3$ & $\mathrm{~F} 4$ & $\mathrm{~F} 5$ & 0,681 \\
$\mathrm{X}_{2}$ & 0,197 & $\mathbf{0 , 6 3 5}$ & $-0,070$ & 0,425 & $-0,231$ & 0,787 \\
$\mathrm{X}_{3}$ & $-0,001$ & 0,037 & 0,368 & 0,057 & $-0,139$ & 0,160 \\
$\mathrm{X}_{7}$ & $\mathbf{0 , 6 7 1}$ & 0,118 & $-0,297$ & $-0,466$ & $-0,088$ & 0,778 \\
$\mathrm{X}_{8}$ & 0,064 & $\mathbf{0 , 8 6 1}$ & $-0,042$ & 0,067 & $-0,029$ & 0,753 \\
$\mathrm{X}_{9}$ & 0,039 & 0,057 & $-0,168$ & 0,128 & $\mathbf{0 , 8 0 9}$ & 0,704 \\
$\mathrm{X}_{10}$ & 0,196 & $\mathbf{0 , 8 3 4}$ & $-0,003$ & 0,078 & 0,156 & 0,764 \\
$\mathrm{X}_{12}$ & 0,050 & $-0,221$ & $\mathbf{0 , 8 9 2}$ & 0,096 & $-0,082$ & 0,863 \\
$\mathrm{X}_{13}$ & 0,303 & $\mathbf{- 0 , 6 0 1}$ & 0,348 & 0,254 & $-0,320$ & 0,741 \\
$\mathrm{X}_{14}$ & 0,101 & $-0,247$ & $\mathbf{0 , 5 8 8}$ & 0,378 & $-0,346$ & 0,680 \\
$\mathrm{X}_{15}$ & $\mathbf{0 , 7 8 3}$ & 0,151 & 0,182 & 0,147 & $-0,283$ & 0,770 \\
$\mathrm{X}_{16}$ & 0,079 & 0,070 & 0,178 & $\mathbf{0 , 6 5 9}$ & 0,248 & 0,538 \\
$\mathrm{X}_{17}$ & $\mathbf{0 , 8 7 5}$ & 0,079 & 0,120 & 0,217 & 0,118 & 0,847 \\
$\mathrm{X}_{18}$ & $\mathbf{0 , 6 7 7}$ & 0,011 & 0,103 & 0,298 & 0,349 & 0,680 \\
$\mathrm{X}_{21}$ & 0,312 & 0,196 & $-0,122$ & $\mathbf{0 , 6 0 8}$ & $-0,083$ & 0,527 \\
\hline
\end{tabular}

Fonte: Resultado da pesquisa, 2012.

Percebe-se que o fator $\mathrm{F}_{1}$ está positiva e fortemente relacionado com os indicadores $\mathrm{X}_{7}$ (área plantada com arroz/área plantada total) $\mathrm{X}_{15}$ (produtividade da terra na cultura do algodão) $\mathrm{X}_{17}$ (matrícula total do ensino fundamental/número de professores do ensino fundamental) e $\mathrm{X}_{18}$ (matrícula total do ensino médio/número de professores do ensino médio). $\mathrm{O}$ fator $\mathrm{F}_{1}$ se refere basicamente ao grupo de intensidade e exploração da terra $\left(G_{1}\right)$ e ao grupo de educação $\left(G_{4}\right)$.

$\mathrm{O}$ fator $\mathrm{F}_{2}$ apresenta direta e elevada relação com os indicadores $\mathrm{X}_{1}$ (número de bovinos/número de estabelecimentos com bovinos) $\mathrm{X}_{8}$ (área plantada com feijão/ área plantada total) e $\mathrm{X}_{10}$ (produtividade da terra na cultura do milho); no entanto, $\mathrm{F}_{2}$ está negativamente relacionado com o indicador $\mathrm{X}_{13}$ (produtividade da terra na cultura da soja). Dentre os indicadores, constata-se que $\mathrm{F}_{2}$ exibe acentuada relação com a variável pertencente ao grupo de escala, pecuarização e modernização da pecuária $\left(G_{2}\right)$, ao grupo intensidade e exploração da terra $\left(G_{1}\right)$ e negativamente relacionado ao grupo de desempenho na agricultura e desenvolvimento econômico $\left(G_{3}\right)$.

Além disso, nota-se que $\mathrm{F}_{3}$ está direta e altamente relacionado com os indica- 
dores $\mathrm{X}_{2}$ (número de suínos/número de bovinos), que pertence ao grupo de escala, pecuarização e modernização da pecuária $\left(G_{2}\right) X_{12}$ (área com lavoura/área total) e $X_{14}$ (produtividade da terra na cultura do algodão): ambos pertencentes ao grupo de desempenho na agricultura e desenvolvimento econômico $\left(G_{3}\right)$.

Por sua vez, o fator $\mathrm{F}_{4}$ está positiva e acentuadamente relacionado com as variáveis $\mathrm{X}_{16}$ (produtividade da terra na cultura da cana-de-açúcar) e $\mathrm{X}_{21}$ (benefícios concedidos pelo INSS/população total do município), que, respectivamente, fazem parte dos grupos: desempenho na agricultura e desenvolvimento econômico $\left(G_{3}\right)$ e saúde e previdência $\left(G_{6}\right)$. Por último, nota-se que o fator $\mathrm{F}_{5}$ está expressiva e diretamente relacionado com apenas uma variável: $\mathrm{X}_{9}$ (área plantada com mandioca/área plantada total), pertencente ao grupo intensidade e exploração da terra $\left(G_{1}\right)$.

Como destaque, um dos fatores que impulsionam o grupo intensidade e exploração da terra $\left(G_{1}\right)$ abriga as variáveis: energia elétrica, recursos financeiros, mão de obra e tecnologia, explicitando que a mão de obra se qualifica e se potencializa pela educação. Quanto à saúde, podem ser citados programas governamentais voltados para conscientização da população, assim como para o controle e a prevenção de doenças, dentre outros.

Em singular, ao se focar a Tabela 4, observa-se que os valores estimados relativos a 2008 apontam que as variáveis também têm sua variabilidade captada e representada por cinco fatores. A única que não exibe valores acima de 0,50 é a $\mathrm{X}_{17}$.

Tabela 4. Cargas Fatoriais e Comunalidades: 2008

(Continua)

\begin{tabular}{ccccccc}
\hline \multirow{2}{*}{ Variáveis } & \multicolumn{5}{c}{ Cargas Fatoriais } & \multirow{2}{*}{ Comunalidades } \\
\cline { 2 - 5 } & $\mathbf{F 1}$ & $\mathbf{F 2}$ & $\mathbf{F 3}$ & $\mathbf{F 4}$ & $\mathbf{F 5}$ & \\
\hline $\mathrm{X}_{1}$ & $-0,100$ & $-0,256$ & $\mathbf{0 , 7 8 2}$ & 0,055 & $-0,173$ & 0,721 \\
$\mathrm{X}_{2}$ & 0,041 & $\mathbf{0 , 7 9 2}$ & 0,001 & $-0,076$ & 0,046 & 0,637 \\
$\mathrm{X}_{3}$ & 0,065 & $\mathbf{0 , 7 2 0}$ & 0,061 & 0,027 & 0,084 & 0,534 \\
$\mathrm{X}_{7}$ & $-0,147$ & $-0,304$ & 0,152 & $-\mathbf{0 , 7 3 8}$ & $-0,005$ & 0,681 \\
$\mathrm{X}_{8}$ & $-0,448$ & 0,105 & 0,083 & $-0,036$ & $-0,582$ & 0,558 \\
$\mathrm{X}_{9}$ & $\mathbf{- 0 , 7 8 9}$ & $-0,085$ & $-0,102$ & 0,106 & 0,003 & 0,651 \\
$\mathrm{X}_{10}$ & $-0,305$ & 0,216 & $\mathbf{0 , 5 0 7}$ & $-0,265$ & $-0,478$ & 0,696 \\
$\mathrm{X}_{12}$ & 0,369 & $\mathbf{0 , 7 7 3}$ & $-0,171$ & 0,205 & 0,091 & 0,813 \\
$\mathrm{X}_{13}$ & $\mathbf{0 , 8 3 7}$ & 0,055 & $-0,171$ & 0,023 & 0,179 & 0,765 \\
& & & & & & \\
\hline
\end{tabular}


Conclusão

\begin{tabular}{ccccccc}
\hline \multirow{2}{*}{ Variáveis } & \multicolumn{5}{c}{ Cargas Fatoriais } & \multirow{2}{*}{ Comunalidades } \\
\cline { 2 - 5 } & F1 & F2 & F3 & F4 & F5 & \\
\hline$X_{14}$ & $\mathbf{0 , 5 1 8}$ & 0,488 & $-0,287$ & 0,346 & $-0,077$ & 0,714 \\
$X_{15}$ & $\mathbf{0 , 7 5 7}$ & 0,254 & $-0,161$ & 0,147 & $-0,003$ & 0,685 \\
$X_{16}$ & $-0,107$ & $-0,103$ & 0,283 & $\mathbf{0 , 7 6 4}$ & 0,171 & 0,716 \\
$X_{17}$ & $-0,078$ & 0,321 & $-0,291$ & $-0,443$ & 0,441 & 0,584 \\
$X_{18}$ & $-0,059$ & 0,254 & 0,114 & 0,075 & $\mathbf{0 , 7 5 2}$ & 0,653 \\
$X_{21}$ & $-0,051$ & 0,105 & $\mathbf{0 , 7 3 6}$ & 0,114 & 0,151 & 0,591 \\
\hline
\end{tabular}

Fonte: Resultado da pesquisa, 2012.

Nota-se que $\mathrm{F}_{1}$ está alta e positivamente relacionado com o indicador $\mathrm{X}_{13}$ (produtividade da terra na cultura da soja) e com o $\mathrm{X}_{14}$ (produtividade da terra na cultura do algodão), mas negativamente relacionado com $\mathrm{X}_{9}$ (área plantada com mandioca/área plantada total).

Por seu turno, $\mathrm{F}_{2}$ se relaciona com os indicadores $\mathrm{X}_{2}$ (número de bovinos/ número de estabelecimentos com bovinos), $\mathrm{X}_{3}$ (número de aves/números de bovinos) e $\mathrm{X}_{12}$ (área plantada com lavoura/área total) Desse modo, esses fatores contribuem de maneira expressiva para o desenvolvimento rural do Estado. Em adição, vê-se que $\mathrm{F}_{3}$ apresenta relação direta e positiva com $\mathrm{X}_{1}$ (número de bovinos/área total), $\mathrm{X}_{10}$ (área plantada com milho/área plantada total) e $\mathrm{X}_{21}$ (benefícios concedidos pelo INSS/população total do município).

Ademais, verifica-se que $\mathrm{F}_{4}$ mantém relação direta ou positiva com $\mathrm{X}_{16}$ (produtividade da terra na cultura da cana-de-açúcar), mas se relaciona negativamente com $\mathrm{X}_{7}$ (área plantada com arroz/área plantada total). Por sua vez, $\mathrm{F}_{5}$ apresenta relação positiva com $\mathrm{X}_{18}$ (matrícula do ensino médio/número de professores do ensino médio) e negativa com $\mathrm{X}_{8}$ (área plantada com feijão/área plantada total). A influência positiva exercida pela produtividade da cana-de-açúcar, por natural, impulsiona o desenvolvimento rural dos municípios. Em singular, as relações negativas sinalizam que a causa dos efeitos contrários sobre o mesmo desenvolvimento se explica pelo elevado número de pequenos produtores de arroz e feijão.

Dessa maneira, se verificou nos anos abordados (2000 e 2008) que as variáveis $\left(\mathrm{X}_{1}, \mathrm{X}_{2}, \mathrm{X}_{3}, \mathrm{X}_{7}, \mathrm{X}_{8}, \mathrm{X}_{4}, \mathrm{X}_{5} \mathrm{X}_{7}, \mathrm{X}_{8}, \mathrm{X}_{9}, \mathrm{X}_{10}, \mathrm{X}_{12}, \mathrm{X}_{13}, \mathrm{X}_{14}, \mathrm{X}_{15}, \mathrm{X}_{16}, \mathrm{X}_{17}, \mathrm{X}_{18}\right.$ e $\left.\mathrm{X}_{21}\right)$, com 
maior ou menor intensidade, exibiram influência significativa no desenvolvimento rural dos municípios. Em particular, o grupo Intensidade e Exploração da Terra $\left(G_{1}\right)$ contempla o efeito da área cultivada, o grupo Escala, Pecuarização e Modernização da Pecuária $\left(G_{2}\right)$ afere o reflexo da pecuária e sua dinâmica, o grupo Desempenho na Agricultura e Desenvolvimento Econômico $\left(G_{3}\right)$ condensa a contribuição da produtividade da terra de diversos bens, enquanto os grupos Saúde e Previdência $\left(G_{5}\right)$ e Degradação Ambiental $\left(G_{6}\right)$, respectivamente, internalizam os efeitos dos rendimentos previdenciários e do desmatamento.

Uma vez caminhados esses passos, ou seja, depois da identificação das variáveis que mais explicam as cargas fatoriais, o próximo passo contempla as estimativas dos escores fatoriais para todos os municípios de Mato Grosso, bem como para os do Vale do Rio Cuiabá, cujos valores encontram-se nos Anexos 1 e 2, mostrando a posição dos municípios, os índices brutos, os índices de desenvolvimento rural e os valores dos fatores para os anos de 2000 e 2008.

A partir dos dados dos Anexos 1 e 2, adota-se a seguinte fórmula para se contrastar, de forma agregada, o desenvolvimento rural dos municípios do Vale do Rio Cuiabá com os do Estado como um todo:

$$
\mathrm{IDR}=\frac{\sum_{\mathrm{i}}^{13} \text { IDR Vale do Rio Cuiabá }}{\sum_{\mathrm{i}}^{141} \text { IDR Estado }}
$$

De acordo com os resultados, a participação relativa do índice de desenvolvimento do Vale do Rio Cuiabá no índice da economia de Mato Grosso como todo em $2008(0,06)$ foi inferior ao de $2000(0,10)$, revelando que nesse intervalo de tempo declinou a representatividade do desenvolvimento rural das economias do Vale na economia estadual, confirmando a hipótese desta pesquisa. Ainda comparando 2000 com 2008, como se verifica na Tabela 5, nota-se que os municípios do Vale que apresentaram decréscimo de posição no índice de desenvolvimento rural durante os dois anos analisados foram: Acorizal, Barão de Melgaço, Jangada, Nossa Senhora do Livramento, Poconé, Rosário Oeste e Várzea Grande.

Tabela 5. Ranking dos municípios do Vale do rio Cuiabá: 2000 e 2008

$$
\text { Municípios Ranking em 2000 Ranking em } 2008
$$


Acorizal

Barão de Melgaço

Chapada dos Guimarães

Cuiabá

Jangada

Nobres

Nossa Senhora do Livramento

Nova Brasilândia

Planalto da Serra

Poconé

Rosário Oeste

Santo Antônio do Leverger

Várzea Grande
28

44

102

23

40

64

45

81

100

86

17

66

47
140

139

28

132

97

48

138

68

53

128

108

13

130

Fonte: Resultado da pesquisa, 2012.

Ainda com foco na Tabela 5, percebe-se que os municípios que exibiram elevação em seu índice de desenvolvimento rural entre 2000 e 2008 foram: Chapada dos Guimarães, Nobres, Nova Brasilândia, Planalto da Serra e Santo Antônio do Leverger. Esse último apresentou melhor IDR em 2008, ocupando a $13^{\mathrm{a}}$ posição no ranking dos municípios, enquanto em 2000, o município que vivenciou melhor desempenho foi Rosário Oeste ( $17^{\mathrm{a}}$ posição). De modo geral, esses resultados ratificam que os municípios do Vale do Rio Cuiabá apresentam baixos índices de desenvolvimento rural.

Por outro lado, dentre os principais municípios do Estado com destacados desempenhos no desenvolvimento rural, se realça Lucas do Rio Verde, cuja agropecuária sobressai pelo cultivo de soja e de algodão, mantendo-se na primeira posição do ranking dos municípios, tanto em 2000, quanto em 2008. O município de Lucas do Rio Verde, além de outros como Primavera do Leste, Campo Verde, Sorriso, Campo Novo do Parecis e Nova Mutum, que surgiram há poucos anos, ou seja, são mais jovens que a grande maioria dos municípios que formam o Vale do Rio Cuiabá, podem ser considerados representativos dos municípios que se especializaram, sobretudo, na sojicultora e na cotonicultura, e que, em decorrência, vivenciam as 
aventuras e os benefícios da prática de uma agricultura moderna, com adoção de tecnologias extremamente intensivas em capital e conhecimento, além de ser habitada por organizações globalizadas e altamente competitivas.

Considerando essas circunstâncias, infere-se que as atividades com centralidade nos setores mais dinâmicos, como a sojicultora e a cotonicultura, desenvolvidas, por oportuno, em estrutura fundiária extremamente concentrada e presentes majoritariamente nas economias dos municípios como Lucas do Rio Verde, Primavera do Leste, Campo Verde, Sorriso, Campo Novo do Parecis e Nova Mutum, a partir da exitosa junção de elementos do desenvolvimento exógeno e endógeno, vêm provocando resultados efetivos e eficientes sobre o desenvolvimento rural das economias desses municípios.

Outrossim, esses resultados diferem substancialmente dos obtidos pelas economias dos municípios onde predominam as ações empreendidas pela agricultura familiar, restritas ao desenvolvimento local, usualmente ancoradas em pequenas unidades produtivas e que estão presentes na grande maioria dos municípios que formam o Vale do Rio Cuiabá. Assim sendo, em decorrência da supremacia desse ente nesse espaço, verifica-se que os efeitos externos ou exógenos produzidos pela agricultura familiar são parcos ou nulos, dado que as forças produtivas germinadas e disseminadas por essa categoria se limitam à economia interna e ao desenvolvimento local.

\section{CONSIDERAÇÕES FINAIS}

Como exigência de adaptação das técnicas atuais de produção à concorrência inerente ao modo de produção capitalista, potencializada pela globalização dos mercados, dentre outros imperativos desse modo de produção, o crescimento econômico das diversas regiões mato-grossenses não vem ocorrendo de maneira homogênea. Esse processo se infiltra na economia regional, influenciando de maneira heterogênea as economias dos diferentes municípios mato-grossenses.

Nesse cenário, as atividades que movimentam a produção de soja, milho, algodão e outros poucos bens agropastoris têm sido responsáveis pela maior parte do crescimento e do desenvolvimento vivenciados pela economia mato-grossense nos anos mais recentes. A imigração de novas e competitivas organizações, junta- 
mente com as já instaladas, contribui fortemente para que esse crescimento e esse desenvolvimento se materializem com expressiva e ascendente desigualdade espacial, visto que os entes que migram para a economia de Mato Grosso se instalam nos municípios com economias mais dinâmicas, pelas diversas externalidades positivas que o adensamento da população de organizações proporciona.

Por conseguinte, como a ordenação dos municípios mato-grossenses com maior ou menor índice de desenvolvimento rural vem se alterando de modo substancial, com estatísticas de 2000 e de 2008, procurou-se avançar na identificação das métricas de desenvolvimento rural desses municípios, com lente especialmente voltada para as economias que formam o Vale do Rio Cuiabá. A hipótese desta pesquisa foi que os municípios que habitam esse espaço apresentam índices de desenvolvimento rural inferiores aos de outros tantos muncípios de Mato Grosso. Os resultados ratificaram essa hipótese.

A conjunção entre as forças exógenas à economia de Mato Grosso e as características do desenvolvimento local ou endógeno, estabelecidas em estrutura fundiária extremamente concentrada, em conjunção, explicam a recente e ascendente concentração espacial dos resultados do desenvolvimento rural na economia do Estado. Embora a base econômica dos municípios que compõem o Vale do Rio Cuiabá, nos anos mais recentes, seja também receptora dos principais bens da economia de Mato Grosso como um todo, como a soja, milho e algodão, nas economias desses municípios ainda predominam as forças produtivas ancoradas na agricultura familiar.

Destarte, os baixos índices de desenvolvimento rural apresentados pelo conjunto de municípios que formam o Vale do Rio Cuiabá são explicados, fundamentalmente, pela dominância das forças produtivas mobilizadas pela agricultura familiar e pela pequena propriedade rural que lhe é intrínseca, moldadas nas fronteiras do desenvolvimento local, que diferem substancialmente das economias dos municípios onde predominam as organizações mais eficientes e competitivas, protagonistas de ações e estratégias que conciliam o desenvolvimento exógeno com o local.

À luz desse raciocínio, é imediato se inferir que as transformações econômicas que vêm sendo vivenciadas nos vários espaços agropecuários de Mato Grosso induzem e potencializam as desigualdades regionais, requerendo, assim, a estratégica participação do Estado através da formulação e adoção de apropriadas políticas 
públicas, preferencialmente direcionadas para as economias menos dinâmicas, povoadas, em supremacia, refirmando-se pela agricultura familiar.

\section{REFERÊNCIAS}

BEZERRA, F. A. Análise Fatorial. In: CORRAR, L. J.; PAUlO, E.; DIAS FILHO, J. M. (Org.). Análise Multivariada. São Paulo: Atlas, 2007.

CORRAR, L. J.; PAULO, E.; DIAS FILHO, J. M. Análise multivariada para os cursos de administração, ciências contábeis e economia. São Paulo: Atlas, 2007.

IBGE - Instituto Brasileiro de Geografia e Estatística. Disponível em: < http://www. sidra.ibge.gov.br/>. Acesso em: 08 ago. 2011.

KAGEYAMA, A. A. Desenvolvimento rural: conceito e um exemplo de medida. In: CONGRESSO DA SOBER, 42., 2004, Cuiabá. Anais... Brasília: SOBER, 2004.

MELO, C. O.; PARRÉ, J. L. Índice de desenvolvimento rural dos municípios paranaenses: determinantes e hierarquização. Revista de Economia e Sociologia Rural. Brasília, v. 45, n. 2, abr.jun. 2007.

MINGOTTI, S. A.; Análise de dados através de métodos de estatística multivariada: uma abordagem aplicada. Belo Horizonte: Ed. UFMG, 2005.

PEREIRA, B. D.; OYAMADA, C. G.; SILVA, G. R.; FARIA, A. de M.; SEBA, M. A.; Determinantes e Hierarquização do Índice de Desenvolvimento Rural nos municípios Mato-grossenses. In: CONGRESSO DA SOBER, 46., 2008, Rio Branco. Anais... Brasília: SOBER, 2008.

SEPLAN/MT - Secretaria do Estado de Planejamento e Coordenação Geral. Anuário Estatístico de Mato Grosso, 2001, 2002 e 2009. Cuiabá: SEPLAN/MT. Disponível em: < http://www.anuario.seplan.mt.gov.br/> Acesso em: 09 maio. 2011.

STEGE, A. L.; PARRÉ, J. L. Desenvolvimento rural nas microrregiões do Brasil: um 
estudo multidimensional. Teoria e Evidência Econômica, v. 17, n. 37, p. 160-193, jul./dez. 2011.

TERLUIN, I. J. Differences in economic development in rural regions of advanced countries: an overview and a critical analysis of theories. Journal of Rural Studies. v. 19, n. 9, p. 327-344, 2003.

Recebido em: 16/01/2016 Aceito em: 01/10/2017

Anexo 1. Índice de Desenvolvimento Rural (IDR) e Classificação dos Municípios de Mato Grosso com base no IDR: 2000

(Continua)

\begin{tabular}{|c|c|c|c|c|c|c|c|c|}
\hline Posição & Municípios & $\mathrm{F} 1$ & $\mathrm{~F} 2$ & $\mathrm{~F} 3$ & $\mathrm{~F} 4$ & F5 & IBD & IDR \\
\hline 1 & Lucas do Rio Verde & 0,120 & 0,477 & 6,585 & $-1,530$ & 1,782 & 1,167 & 100,000 \\
\hline 2 & Mirassol d'Oeste & $-0,010$ & 3,116 & 0,502 & 0,385 & $-1,303$ & 0,919 & 89,088 \\
\hline 3 & Jauru & $-0,444$ & 2,881 & 0,048 & 1,690 & $-0,336$ & 0,902 & 88,363 \\
\hline 4 & Araputanga & $-0,135$ & 2,748 & $-0,105$ & 1,129 & $-0,594$ & 0,843 & 85,761 \\
\hline 5 & Sorriso & 0,099 & 0,045 & 5,680 & $-1,796$ & 1,491 & 0,832 & 85,246 \\
\hline 6 & Indiavaí & $-0,211$ & 2,640 & 0,051 & 0,641 & 0,016 & 0,816 & 84,553 \\
\hline 7 & Reserva do Cabaçal & 0,550 & 1,640 & $-0,214$ & 0,745 & 0,080 & 0,739 & 81,146 \\
\hline 8 & Figueirópolis D’Oeste & $-0,127$ & 2,462 & $-0,007$ & 0,691 & $-0,870$ & 0,692 & 79,077 \\
\hline 9 & Rio Branco & 0,271 & 2,142 & $-0,910$ & 1,674 & $-1,051$ & 0,689 & 78,941 \\
\hline 10 & Salto do Céu & $-0,546$ & 2,740 & 0,131 & 0,549 & $-0,487$ & 0,685 & 78,786 \\
\hline 11 & Nova Monte Verde & 0,012 & 2,130 & 0,277 & $-0,861$ & 0,318 & 0,618 & 75,815 \\
\hline 12 & $\begin{array}{c}\text { São José dos Quatro } \\
\text { Marcos }\end{array}$ & $-0,304$ & 2,633 & 0,115 & 0,401 & $-1,485$ & 0,604 & 75,195 \\
\hline 13 & Cáceres & 0,214 & 1,103 & $-0,041$ & 0,965 & 0,745 & 0,592 & 74,694 \\
\hline 14 & Pontes e Lacerda & 0,037 & 1,690 & 0,051 & 0,575 & $-0,226$ & 0,575 & 73,938 \\
\hline 15 & Porto Esperidião & $-0,297$ & 1,880 & 0,187 & 0,337 & $-0,253$ & 0,514 & 71,232 \\
\hline 16 & Juína & $-0,346$ & 1,751 & 0,097 & 0,120 & 0,592 & 0,509 & 71,047 \\
\hline
\end{tabular}


(Continua)

\begin{tabular}{|c|c|c|c|c|c|c|c|c|}
\hline Posição & Municípios & $\mathrm{F} 1$ & $\mathrm{~F} 2$ & F3 & $\mathrm{F} 4$ & F5 & IBD & IDR \\
\hline 17 & Rosário Oeste & 1,215 & $-0,782$ & $-0,548$ & 1,405 & 2,376 & 0,497 & 70,522 \\
\hline 18 & Paranaíta & 1,960 & $-0,161$ & $-0,576$ & $-0,849$ & 0,762 & 0,475 & 69,523 \\
\hline 19 & Nova Olímpia & 0,899 & $-0,785$ & $-0,091$ & 1,607 & 2,199 & 0,468 & 69,235 \\
\hline 20 & $\begin{array}{c}\text { Vila Bela da Santíssima } \\
\text { Trindade }\end{array}$ & 0,235 & 1,523 & $-0,084$ & $-0,635$ & 0,164 & 0,463 & 69,017 \\
\hline 21 & Cotriguaçu & $-0,290$ & 1,333 & 0,378 & $-0,489$ & 1,357 & 0,451 & 68,475 \\
\hline 22 & Denise & 0,731 & $-0,580$ & 0,255 & 1,683 & 1,353 & 0,446 & 68,269 \\
\hline 23 & Cuiabá & $-0,016$ & 0,627 & $-0,182$ & 0,249 & 2,188 & 0,421 & 67,159 \\
\hline 24 & Vila Rica & $-0,207$ & 1,700 & 0,046 & $-0,526$ & 0,181 & 0,409 & 66,626 \\
\hline 25 & Juruena & $-0,399$ & 1,606 & $-0,111$ & $-0,018$ & 0,663 & 0,409 & 66,608 \\
\hline 26 & Campo Verde & $-0,290$ & 0,218 & 3,810 & 0,201 & $-1,520$ & 0,400 & 66,246 \\
\hline 27 & Apiacás & 0,628 & 0,758 & $-0,149$ & $-0,890$ & 0,907 & 0,398 & 66,136 \\
\hline 28 & Acorizal & $-0,289$ & 0,545 & $-0,418$ & 0,831 & 2,660 & 0,394 & 65,973 \\
\hline 29 & Confresa & $-0,073$ & 0,080 & 0,372 & 0,689 & 2,266 & 0,381 & 65,404 \\
\hline 30 & Alta Floresta & 0,857 & 0,907 & $-0,629$ & $-0,139$ & $-0,563$ & 0,379 & 65,301 \\
\hline 31 & Aripuanã & 0,133 & 0,952 & $-0,021$ & $-0,636$ & 0,778 & 0,333 & 63,293 \\
\hline 32 & Castanheira & 0,085 & 1,069 & $-0,376$ & 0,089 & 0,228 & 0,329 & 63,100 \\
\hline 33 & Porto Estrela & 0,326 & 0,179 & 0,132 & 0,986 & 0,129 & 0,312 & 62,333 \\
\hline 34 & Nova Guarita & 0,841 & 0,654 & $-0,076$ & $-0,731$ & $-0,733$ & 0,290 & 61,361 \\
\hline 35 & Carlinda & 0,757 & 0,696 & 0,005 & $-1,179$ & $-0,283$ & 0,281 & 61,002 \\
\hline 36 & Peixoto de Azevedo & 1,240 & $-0,101$ & $-0,259$ & $-1,098$ & 0,764 & 0,279 & 60,889 \\
\hline 37 & Juara & 0,664 & 0,750 & $-0,531$ & $-0,725$ & $-0,082$ & 0,264 & 60,252 \\
\hline 38 & São José do Povo & 0,128 & 0,767 & $-0,036$ & $-0,028$ & $-0,036$ & 0,260 & 60,060 \\
\hline 39 & Sinop & 1,112 & $-0,626$ & 1,381 & $-0,681$ & $-0,313$ & 0,258 & 59,966 \\
\hline 40 & Jangada & $-0,071$ & $-0,438$ & $-0,377$ & 1,419 & 2,630 & 0,242 & 59,256 \\
\hline 41 & Colíder & 0,581 & 0,606 & $-0,537$ & 0,699 & $-1,263$ & 0,240 & 59,171 \\
\hline 42 & União do Sul & 1,713 & 0,005 & $-0,427$ & $-1,989$ & $-0,079$ & 0,240 & 59,165 \\
\hline 43 & Marcelândia & 1,251 & 0,019 & $-0,498$ & $-1,234$ & 0,476 & 0,236 & 58,993 \\
\hline 44 & Barão de Melgaço & $-0,441$ & 0,357 & $-0,449$ & 0,627 & 2,420 & 0,233 & 58,890 \\
\hline 45 & $\begin{array}{l}\text { Nossa Senhora do } \\
\text { Livramento }\end{array}$ & $-0,536$ & 0,156 & $-0,165$ & 0,319 & 3,223 & 0,233 & 58,880 \\
\hline 46 & Ponte Branca & 0,698 & 0,296 & $-0,628$ & $-0,399$ & 0,523 & 0,228 & $\begin{array}{l}58 \\
643\end{array}$ \\
\hline
\end{tabular}


(Continua)

\begin{tabular}{|c|c|c|c|c|c|c|c|c|}
\hline Posição & Municípios & $\mathrm{F} 1$ & $\mathrm{~F} 2$ & F3 & F4 & F5 & IBD & IDR \\
\hline 47 & Várzea Grande & $-0,108$ & $-0,708$ & $-0,641$ & 0,846 & 4,281 & 0,216 & 58,131 \\
\hline 48 & Arenápolis & 1,236 & 0,172 & $-0,827$ & 0,130 & $-1,183$ & 0,216 & 58,109 \\
\hline 49 & Nova Bandeirantes & 0,345 & 0,931 & $-0,075$ & $-1,525$ & 0,086 & 0,206 & 57,666 \\
\hline 50 & Nova Canaã do Norte & 0,305 & 0,748 & $-0,320$ & $-0,102$ & $-0,596$ & 0,200 & 57,423 \\
\hline 51 & Terra Nova do Norte & 0,013 & 1,209 & $-0,308$ & $-0,110$ & $-1,031$ & 0,200 & 57,405 \\
\hline 52 & $\begin{array}{l}\text { Novo Horizonte do } \\
\text { Norte }\end{array}$ & 0,765 & 0,712 & $-0,330$ & $-1,085$ & $-0,844$ & 0,190 & 56,994 \\
\hline 53 & Guarantã do Norte & 0,769 & 0,434 & $-0,300$ & $-0,802$ & $-0,468$ & 0,187 & 56,833 \\
\hline 54 & Itaúba & 1,267 & $-0,296$ & $-0,461$ & $-0,314$ & $-0,267$ & 0,183 & 56,663 \\
\hline 55 & Alto Taquari & 0,531 & $-0,698$ & 2,158 & 0,163 & $-1,122$ & 0,181 & 56,558 \\
\hline 56 & Jaciara & 0,046 & $-0,603$ & 0,978 & 2,178 & $-0,882$ & 0,148 & 55,117 \\
\hline 57 & Santa Carmem & 1,909 & $-1,121$ & $-0,431$ & $-0,858$ & 0,342 & 0,144 & 54,962 \\
\hline 58 & Santa Terezinha & 0,313 & $-0,771$ & $-0,598$ & 0,054 & 3,179 & 0,125 & 54,125 \\
\hline 59 & Dom Aquino & 0,178 & $-0,868$ & 0,459 & 2,511 & $-0,452$ & 0,119 & 53,857 \\
\hline 60 & Rondonópolis & $-0,159$ & $-0,431$ & 0,865 & 1,785 & $-0,440$ & 0,117 & 53,741 \\
\hline 61 & Porto Alegre do Norte & 0,995 & $-0,521$ & $-0,455$ & 0,128 & $-0,006$ & 0,110 & 53,455 \\
\hline 62 & Campinápolis & 0,298 & 0,319 & $-0,626$ & $-0,147$ & 0,185 & 0,101 & 53,054 \\
\hline 63 & Comodoro & 1,035 & $-0,481$ & $-0,395$ & $-0,190$ & $-0,262$ & 0,078 & 52,039 \\
\hline 64 & Nobres & 0,453 & $-0,809$ & 0,219 & 1,366 & $-0,227$ & 0,075 & 51,927 \\
\hline 65 & Tangará da Serra & 0,372 & $-0,644$ & 0,603 & 1,294 & $-0,962$ & 0,069 & 51,643 \\
\hline 66 & $\begin{array}{l}\text { Santo Antônio do } \\
\text { Leverger }\end{array}$ & $-0,478$ & 0,426 & $-0,376$ & 1,029 & 0,198 & 0,065 & 51,455 \\
\hline 67 & Canabrava do Norte & 0,237 & 0,573 & $-0,241$ & $-1,441$ & 0,144 & 0,054 & 51,004 \\
\hline 68 & Juscimeira & $-0,163$ & $-0,252$ & $-0,107$ & 1,896 & $-0,358$ & 0,047 & 50,666 \\
\hline 69 & Glória D’Oeste & $-0,155$ & 0,481 & $-0,091$ & $-0,159$ & $-0,189$ & 0,042 & 50,474 \\
\hline 70 & Ribeirão Cascalheira & 0,609 & 0,365 & $-0,557$ & $-1,137$ & $-0,428$ & 0,040 & 50,363 \\
\hline 71 & Guiratinga & 0,237 & $-0,967$ & 0,196 & 2,059 & $-0,233$ & 0,038 & 50,285 \\
\hline 72 & Diamantino & 0,027 & $-1,001$ & 1,427 & 1,093 & $-0,153$ & 0,035 & 50,133 \\
\hline 73 & Nova Lacerda & 0,745 & $-0,157$ & $-0,040$ & $-0,853$ & $-0,527$ & 0,027 & 49,782 \\
\hline 74 & Nova Mutum & 0,451 & $-0,810$ & 1,276 & $-0,210$ & $-0,492$ & 0,012 & 49,144 \\
\hline 75 & Novo Mundo & 1,010 & 0,050 & $-0,270$ & $-2,070$ & $-0,373$ & 0,009 & 49,008 \\
\hline 76 & Lambari D'Oeste & $-0,088$ & $-0,395$ & $-0,160$ & 1,400 & 0,091 & 0,008 & 48,951 \\
\hline 77 & Luciara & 0,736 & $-0,838$ & $-0,898$ & $-0,691$ & 2,246 & 0,007 & 48,907 \\
\hline
\end{tabular}


(Continua)

\begin{tabular}{|c|c|c|c|c|c|c|c|c|}
\hline Posição & Municípios & $\mathrm{F} 1$ & $\mathrm{~F} 2$ & F3 & $\mathrm{F} 4$ & F5 & IBD & IDR \\
\hline 78 & Primavera do Leste & $-0,097$ & $-0,752$ & 2,040 & $-0,170$ & $-0,174$ & 0,006 & 48,875 \\
\hline 79 & Nortelândia & 0,949 & $-0,813$ & $-0,476$ & 0,304 & $-0,220$ & 0,002 & 48,707 \\
\hline 80 & Cláudia & 1,787 & $-0,976$ & $-0,704$ & $-1,170$ & $-0,305$ & 0,001 & 48,670 \\
\hline 81 & Nova Brasilândia & 0,585 & $-0,192$ & $-0,746$ & 0,146 & $-0,396$ & $-0,005$ & 48,384 \\
\hline 82 & São Pedro da Cipa & $-0,407$ & $-0,139$ & 0,269 & 0,489 & 0,600 & $-0,010$ & 48,178 \\
\hline 83 & Santo Afonso & 0,680 & $-0,607$ & 0,049 & 0,212 & $-0,738$ & $-0,010$ & 48,151 \\
\hline 84 & São José do Xingu & 0,101 & 0,267 & $-0,353$ & $-0,701$ & 0,118 & $-0,012$ & 48,090 \\
\hline 85 & Alto Boa Vista & $-0,087$ & 0,413 & $-0,226$ & $-1,304$ & 0,680 & $-0,022$ & 47,622 \\
\hline 86 & Poconé & $-0,093$ & $-0,490$ & $-0,643$ & 0,952 & 1,246 & $-0,025$ & 47,509 \\
\hline 87 & Araguainha & $-0,210$ & 0,618 & $-0,527$ & $-0,651$ & 0,113 & $-0,026$ & 47,457 \\
\hline 88 & São Félix do Araguaia & 0,166 & 0,117 & $-0,769$ & $-0,558$ & 0,600 & $-0,029$ & 47,327 \\
\hline 89 & Nova Xavantina & 0,530 & $-0,695$ & $-0,081$ & 1,098 & $-1,071$ & $-0,033$ & 47,156 \\
\hline 90 & Tabaporã & 1,204 & $-0,637$ & $-0,386$ & $-1,265$ & $-0,171$ & $-0,034$ & 47,118 \\
\hline 91 & Poxoréo & 0,291 & $-0,704$ & $-0,033$ & 1,519 & $-1,221$ & $-0,071$ & 45,494 \\
\hline 92 & Porto dos Gaúchos & 0,843 & $-0,674$ & $-0,968$ & 0,506 & $-0,574$ & $-0,076$ & 45,251 \\
\hline 93 & Tapurah & 0,105 & $-0,642$ & 1,455 & $-0,642$ & $-0,649$ & $-0,091$ & 44,599 \\
\hline 94 & Água Boa & 1,068 & $-0,547$ & $-0,531$ & $-0,268$ & $-1,487$ & $-0,092$ & 44,567 \\
\hline 95 & Pedra Preta & $-0,059$ & $-0,707$ & 0,456 & 1,626 & $-1,163$ & $-0,092$ & 44,547 \\
\hline 96 & Matupá & 0,980 & $-0,400$ & $-0,324$ & $-1,302$ & $-0,780$ & $-0,094$ & 44,444 \\
\hline 97 & Pontal do Araguaia & 0,092 & 0,244 & $-0,543$ & $-1,457$ & 0,283 & $-0,123$ & 43,170 \\
\hline 98 & Campo Novo do Parecis & $-0,611$ & $-0,962$ & 2,029 & 0,423 & $-0,043$ & $-0,139$ & 42,492 \\
\hline 99 & Feliz Natal & 1,273 & $-0,947$ & $-0,319$ & $-1,712$ & $-0,146$ & $-0,147$ & 42,149 \\
\hline 100 & Planalto da Serra & 0,529 & $-0,186$ & $-0,395$ & $-1,588$ & $-0,156$ & $-0,153$ & 41,845 \\
\hline 101 & Barra do Bugres & $-0,689$ & $-0,374$ & $-0,468$ & 1,587 & 0,545 & $-0,154$ & 41,835 \\
\hline 102 & $\begin{array}{l}\text { Chapada dos Gui- } \\
\text { marães }\end{array}$ & $-0,347$ & $-0,432$ & $-0,259$ & 0,974 & $-0,058$ & $-0,169$ & 41,181 \\
\hline 103 & Vera & 0,893 & $-1,127$ & 0,117 & $-0,546$ & $-0,664$ & $-0,173$ & 40,992 \\
\hline 104 & Alto Garças & $-0,377$ & $-0,727$ & 0,694 & 0,995 & $-0,789$ & $-0,201$ & 39,730 \\
\hline 105 & Cocalinho & 0,796 & $-0,808$ & $-0,700$ & $-0,898$ & $-0,028$ & $-0,204$ & 39,638 \\
\hline 106 & Barra do Garças & 0,346 & $-0,712$ & $-0,867$ & 0,678 & $-0,535$ & $-0,208$ & 39,451 \\
\hline 107 & Canarana & 0,582 & $-0,881$ & $-0,540$ & 0,218 & $-0,744$ & $-0,212$ & 39,262 \\
\hline 108 & Itiquira & $-0,392$ & $-0,935$ & 0,594 & 1,248 & $-0,461$ & $-0,218$ & 39,002 \\
\hline 109 & Torixoréu & 0,166 & $-0,872$ & $-0,294$ & 1,463 & $-1,352$ & $-0,221$ & 38,869 \\
\hline
\end{tabular}


(Continua)

\begin{tabular}{|c|c|c|c|c|c|c|c|c|}
\hline Posição & Municípios & $\mathrm{F} 1$ & $\mathrm{~F} 2$ & F3 & F4 & F5 & IBD & IDR \\
\hline 110 & Nova Marilândia & 0,197 & $-0,553$ & $-0,108$ & $-0,434$ & $-0,468$ & $-0,222$ & 38,813 \\
\hline 111 & Querência & 1,027 & $-1,041$ & $-0,495$ & $-0,692$ & $-0,765$ & $-0,223$ & 38,788 \\
\hline 112 & São José do Rio Claro & 0,024 & $-1,080$ & 0,126 & 1,137 & $-0,669$ & $-0,233$ & 38,330 \\
\hline 113 & Alto Paraguai & $-0,178$ & $-0,969$ & $-0,490$ & 1,400 & 0,139 & $-0,238$ & 38,115 \\
\hline 114 & Novo São Joaquim & $-0,520$ & $-0,787$ & 0,941 & 0,934 & $-0,853$ & $-0,243$ & 37,892 \\
\hline 115 & Alto Araguaia & $-0,432$ & $-0,508$ & $-0,376$ & 1,146 & $-0,497$ & $-0,262$ & 37,047 \\
\hline 116 & Sapezal & $-0,013$ & $-1,161$ & 0,917 & $-0,153$ & $-0,242$ & $-0,263$ & 37,042 \\
\hline 117 & Nova Maringá & 0,613 & $-0,865$ & $-0,300$ & $-0,902$ & $-0,725$ & $-0,295$ & 35,606 \\
\hline 118 & Paranatinga & 0,795 & $-1,060$ & $-0,882$ & $-0,456$ & $-0,504$ & $-0,304$ & 35,200 \\
\hline 119 & Araguaiana & 0,242 & $-0,659$ & $-0,784$ & $-0,298$ & $-0,560$ & $-0,333$ & 33,922 \\
\hline 120 & Brasnorte & $-0,529$ & $-0,855$ & 0,187 & 0,988 & $-0,569$ & $-0,342$ & 33,553 \\
\hline 121 & General Carneiro & $-0,577$ & $-0,797$ & 0,134 & 0,771 & $-0,798$ & $-0,398$ & 31,064 \\
\hline 122 & Gaúcha do Norte & 0,405 & $-1,123$ & $-0,499$ & $-0,720$ & $-0,289$ & $-0,401$ & 30,950 \\
\hline 123 & Tesouro & $-0,196$ & $-0,915$ & $-0,498$ & 0,215 & $-0,236$ & $-0,413$ & 30,433 \\
\hline 124 & Ribeirãozinho & $-0,360$ & $-0,570$ & 0,173 & $-0,640$ & $-0,735$ & $-0,418$ & 30,191 \\
\hline 125 & Nova Ubiratã & $-0,175$ & $-1,098$ & 0,396 & $-0,339$ & $-0,945$ & $-0,471$ & 27,864 \\
\hline 126 & Campos de Júlio & $-1,032$ & $-0,953$ & 1,159 & $-0,553$ & $-0,350$ & $-0,552$ & 24,293 \\
\hline 127 & Santo Antônio do Leste & $-2,361$ & $-0,482$ & $-0,630$ & $-0,469$ & $-0,233$ & $-1,081$ & 1,006 \\
\hline 128 & Bom Jesus do Araguaia & $-2,399$ & $-0,479$ & $-0,489$ & $-0,832$ & $-0,144$ & $-1,105$ & $-0,068$ \\
\hline 129 & Colniza & $-2,399$ & $-0,479$ & $-0,489$ & $-0,832$ & $-0,144$ & $-1,105$ & $-0,068$ \\
\hline 130 & Conquista D'Oeste & $-2,399$ & $-0,479$ & $-0,489$ & $-0,832$ & $-0,144$ & $-1,105$ & $-0,068$ \\
\hline 131 & Curvelândia & $-2,399$ & $-0,479$ & $-0,489$ & $-0,832$ & $-0,144$ & $-1,105$ & $-0,068$ \\
\hline 132 & Ipiranga do Norte & $-2,399$ & $-0,479$ & $-0,489$ & $-0,832$ & $-0,144$ & $-1,105$ & $-0,068$ \\
\hline 133 & Itanhangá & $-2,399$ & $-0,479$ & $-0,489$ & $-0,832$ & $-0,144$ & $-1,105$ & $-0,068$ \\
\hline 134 & Nova Nazaré & $-2,399$ & $-0,479$ & $-0,489$ & $-0,832$ & $-0,144$ & $-1,105$ & $-0,068$ \\
\hline 135 & Nova Santa Helena & $-2,399$ & $-0,479$ & $-0,489$ & $-0,832$ & $-0,144$ & $-1,105$ & $-0,068$ \\
\hline 136 & Novo Santo Antônio & $-2,399$ & $-0,479$ & $-0,489$ & $-0,832$ & $-0,144$ & $-1,105$ & $-0,068$ \\
\hline 137 & Rondolândia & $-2,399$ & $-0,479$ & $-0,489$ & $-0,832$ & $-0,144$ & $-1,105$ & $-0,068$ \\
\hline 138 & Santa Cruz do Xingu & $-2,399$ & $-0,479$ & $-0,489$ & $-0,832$ & $-0,144$ & $-1,105$ & $-0,068$ \\
\hline 139 & Santa Rita do Trivelato & $-2,399$ & $-0,479$ & $-0,489$ & $-0,832$ & $-0,144$ & $-1,105$ & $-0,068$ \\
\hline 140 & Serra Nova Dourada & $-2,399$ & $-0,479$ & $-0,489$ & $-0,832$ & $-0,144$ & $-1,105$ & $-0,068$ \\
\hline 141 & Vale de São Domingos & $-2,399$ & $-0,479$ & $-0,489$ & $-0,832$ & $-0,144$ & $-1,105$ & 0,000 \\
\hline
\end{tabular}


(Conclusão)

\begin{tabular}{|l|l|l|l|l|l|l|l|l|}
\hline Posição & Municípios & F1 & F2 & F3 & F4 & F5 & IBD & IDR \\
\hline
\end{tabular}

Fonte: Resultado da pesquisa, 2012.

Anexo 2. Índice de Desenvolvimento Rural (IDR) e Classificação dos Municípios de Mato Grosso com base no IDR: 2008

(Continua)

\begin{tabular}{|c|c|c|c|c|c|c|c|c|}
\hline Posição & Municípios & $\mathrm{F} 1$ & $\mathrm{~F} 2$ & F3 & F4 & F5 & IBD & IDR \\
\hline 1 & Lucas do Rio Verde & 0,006 & 7,373 & 0,601 & $-1,039$ & 0,110 & 1,318 & 100 \\
\hline 2 & Campo Verde & 0,289 & 3,927 & 0,688 & 0,968 & 0,508 & 1,130 & 92,680 \\
\hline 3 & Diamantino & 0,791 & 1,373 & 0,622 & 1,225 & 1,162 & 0,967 & 86,334 \\
\hline 4 & Jaciara & 1,054 & 0,443 & 0,998 & 1,588 & 0,307 & 0,918 & 84,427 \\
\hline 5 & Dom Aquino & 1,298 & 0,476 & 0,268 & 1,364 & 0,455 & 0,885 & 83,167 \\
\hline 6 & Nova Mutum & 0,360 & 3,765 & 0,033 & $-0,515$ & 0,951 & 0,875 & 82,768 \\
\hline 7 & Mirassol D'Oeste & 0,515 & $-0,485$ & 2,696 & 1,605 & 0,240 & 0,816 & 80,457 \\
\hline 8 & Lambari D'Oeste & 0,288 & $-0,509$ & 1,753 & 1,436 & 2,231 & 0,766 & 78,515 \\
\hline 9 & Tangará da Serra & 0,608 & 0,302 & 0,883 & 1,519 & 0,896 & 0,752 & 77,961 \\
\hline 10 & $\begin{array}{l}\text { Campo Novo dos } \\
\text { Parecis }\end{array}$ & 0,835 & 0,742 & $-0,314$ & 1,500 & 0,510 & 0,672 & 74,868 \\
\hline 11 & Sorriso & 0,609 & 2,358 & $-0,442$ & $-0,181$ & 0,769 & 0,662 & 74,479 \\
\hline 12 & Vera & 0,333 & 3,044 & $-0,326$ & $-0,482$ & 0,139 & 0,583 & 71,416 \\
\hline 13 & $\begin{array}{l}\text { Santo Antônio do } \\
\text { Leverger }\end{array}$ & 1,168 & $-0,305$ & 0,719 & 1,593 & $-1,441$ & 0,581 & 71,311 \\
\hline 14 & $\begin{array}{c}\text { São José dos Quatro } \\
\text { Marcos }\end{array}$ & 0,408 & 0,012 & 3,021 & 0,233 & $-1,153$ & 0,579 & 71,229 \\
\hline 15 & Primavera do Leste & 1,066 & 1,335 & $-0,510$ & 0,541 & $-0,710$ & 0,574 & 71,066 \\
\hline 16 & Guiratinga & 0,897 & 0,269 & $-0,561$ & 0,657 & 1,479 & 0,571 & 70,919 \\
\hline 17 & Itiquira & 0,488 & 0,073 & 0,033 & 1,884 & 0,950 & 0,571 & 70,918 \\
\hline 18 & Campos de Júlio & 0,824 & 0,583 & $-0,337$ & 1,833 & $-0,493$ & 0,564 & 70,642 \\
\hline 19 & Poxoréo & 1,126 & 0,072 & $-0,068$ & 0,973 & $-0,248$ & 0,554 & 70,271 \\
\hline 20 & Alto Taquari & 1,687 & 0,810 & $-1,192$ & 0,524 & $-1,303$ & 0,543 & 69,844 \\
\hline 21 & Juscimeira & 0,922 & $-0,496$ & 0,803 & 1,243 & $-0,339$ & 0,542 & 69,793 \\
\hline 22 & Nova Xavantina & 1,098 & $-0,218$ & $-0,053$ & 0,582 & 0,459 & 0,523 & 69,069 \\
\hline 23 & Pedra Preta & 0,861 & $-0,050$ & 0,297 & 0,803 & 0,041 & 0,498 & 68,098 \\
\hline
\end{tabular}


(Continua)

\begin{tabular}{|c|c|c|c|c|c|c|c|c|}
\hline Posição & Municípios & $\mathrm{F} 1$ & $\mathrm{~F} 2$ & F3 & $\mathrm{F} 4$ & F5 & IBD & IDR \\
\hline 24 & Nova Guarita & 0,921 & $-0,480$ & 2,009 & $-0,534$ & $-0,589$ & 0,489 & 67,724 \\
\hline 25 & Rondonópolis & 0,626 & 0,196 & 0,449 & 0,452 & 0,516 & 0,483 & 67,496 \\
\hline 26 & Sinop & 0,652 & 1,001 & $-0,191$ & $-0,087$ & 0,628 & 0,472 & 67,094 \\
\hline 27 & General Carneiro & 1,532 & 0,099 & $-0,471$ & 1,042 & $-2,326$ & 0,425 & 65,240 \\
\hline 28 & $\begin{array}{c}\text { Chapada dos Gui- } \\
\text { marães }\end{array}$ & 1,242 & $-0,051$ & $-0,037$ & 0,882 & $-1,593$ & 0,418 & 64,962 \\
\hline 29 & Sapezal & 0,768 & 0,886 & $-0,774$ & $-0,174$ & 0,670 & 0,393 & 63,999 \\
\hline 30 & Nortelândia & 0,986 & $-0,165$ & $-0,238$ & 0,439 & 0,023 & 0,387 & 63,774 \\
\hline 31 & Glória D’Oeste & $-0,317$ & $-0,576$ & 2,397 & 1,718 & $-0,344$ & 0,361 & 62,743 \\
\hline 32 & Alta Floresta & 0,754 & $-0,666$ & 1,778 & $-1,629$ & 0,700 & 0,353 & 62,460 \\
\hline 33 & Brasnorte & 0,948 & 0,141 & $-1,075$ & $-0,018$ & 1,016 & 0,339 & 61,903 \\
\hline 34 & Novo Mundo & 1,141 & $-0,573$ & 0,574 & $-0,633$ & $-0,346$ & 0,331 & 61,610 \\
\hline 35 & Nova Marilândia & 1,033 & $-0,340$ & 0,416 & 0,089 & $-0,960$ & 0,327 & 61,444 \\
\hline 36 & Água Boa & 0,933 & $-0,559$ & 0,196 & $-0,471$ & 0,507 & 0,305 & 60,581 \\
\hline 37 & Canarana & 0,847 & $-0,328$ & $-0,171$ & $-0,117$ & 0,514 & 0,297 & 60,260 \\
\hline 38 & São José do Rio Claro & 0,397 & 0,228 & $-1,007$ & 0,998 & 1,179 & 0,296 & 60,226 \\
\hline 39 & Tapurah & 0,844 & 0,806 & $-1,135$ & 0,078 & $-0,283$ & 0,271 & 59,256 \\
\hline 40 & São Félix do Araguaia & 0,707 & $-0,407$ & 0,454 & $-0,239$ & 0,014 & 0,259 & 58,793 \\
\hline 41 & Porto dos Gaúchos & 0,870 & $-0,240$ & 0,106 & 0,340 & $-0,979$ & 0,257 & 58,732 \\
\hline 42 & Arenápolis & $-0,532$ & $-0,544$ & 1,468 & 1,265 & 1,114 & 0,230 & 57,668 \\
\hline 43 & Terra Nova do Norte & 0,612 & $-0,568$ & 1,209 & $-1,034$ & 0,069 & 0,222 & 57,367 \\
\hline 44 & Figueirópolis D’Oeste & $-0,195$ & 0,150 & 2,881 & $-0,450$ & $-1,556$ & 0,201 & 56,550 \\
\hline 45 & Alto Garças & 0,953 & 0,139 & $-1,499$ & 0,523 & $-0,207$ & 0,199 & 56,448 \\
\hline 46 & Pontes e Lacerda & 0,103 & $-0,215$ & 1,123 & 0,309 & $-0,366$ & 0,192 & 56,171 \\
\hline 47 & Ipiranga do Norte & 0,498 & 1,722 & $-1,460$ & $-0,326$ & $-0,341$ & 0,183 & 55,836 \\
\hline 48 & Nobres & 0,448 & $-0,646$ & 0,077 & 0,493 & 0,249 & 0,170 & 55,318 \\
\hline 49 & Araputanga & $-0,888$ & 0,582 & 2,915 & $-0,030$ & $-0,632$ & 0,167 & 55,219 \\
\hline 50 & Santa Carmem & 0,272 & 0,292 & $-0,275$ & $-1,273$ & 1,854 & 0,162 & 55,032 \\
\hline 51 & Vale de São Domingos & 0,305 & $-0,872$ & 0,181 & 1,144 & 0,133 & 0,160 & 54,948 \\
\hline 52 & Cláudia & 0,781 & 0,316 & $-0,643$ & $-0,561$ & $-0,360$ & 0,148 & 54,473 \\
\hline 53 & Planalto da Serra & 0,489 & $-0,451$ & $-0,006$ & $-1,035$ & 1,467 & 0,147 & 54,450 \\
\hline 54 & Querência & 1,212 & $-0,886$ & $-1,124$ & 0,572 & $-0,584$ & 0,145 & 54,336 \\
\hline
\end{tabular}


(Continua)

\begin{tabular}{|c|c|c|c|c|c|c|c|c|}
\hline Posição & Municípios & F1 & $\mathrm{F} 2$ & $\mathrm{~F} 3$ & $\mathrm{~F} 4$ & F5 & IBD & IDR \\
\hline 55 & Alto Araguaia & 0,989 & $-0,585$ & $-1,131$ & 1,357 & $-1,163$ & 0,144 & 54,323 \\
\hline 56 & Comodoro & 0,750 & 0,036 & $-0,526$ & $-0,414$ & $-0,246$ & 0,137 & 54,049 \\
\hline 57 & Tesouro & 1,075 & $-0,049$ & $-1,203$ & 0,343 & $-1,134$ & 0,134 & 53,940 \\
\hline 58 & Ribeirãozinho & 0,847 & $-0,652$ & $-0,563$ & 0,406 & $-0,409$ & 0,133 & 53,906 \\
\hline 59 & Itanhangá & 0,020 & $-0,116$ & $-0,558$ & 0,721 & 1,144 & 0,118 & 53,298 \\
\hline 60 & Nova Canaã do Norte & 0,608 & $-0,539$ & 0,714 & $-1,189$ & $-0,046$ & 0,108 & 52,933 \\
\hline 61 & Novo São Joaquim & 0,908 & $-0,030$ & $-1,106$ & 0,233 & $-0,867$ & 0,103 & 52,735 \\
\hline 62 & Nova Ubiratã & 0,694 & 0,287 & $-1,488$ & 0,042 & 0,161 & 0,103 & 52,712 \\
\hline 63 & Alto Paraguai & 0,640 & $-0,362$ & $-0,034$ & $-0,201$ & $-0,551$ & 0,097 & 52,486 \\
\hline 64 & Torixoréu & 0,742 & $-1,007$ & $-0,510$ & 0,634 & $-0,155$ & 0,095 & 52,402 \\
\hline 65 & Vila Rica & 0,375 & $-0,571$ & 0,757 & $-1,871$ & 1,295 & 0,081 & 51,846 \\
\hline 66 & Paranatinga & 0,615 & $-0,546$ & $-0,353$ & $-0,940$ & 0,969 & 0,077 & 51,725 \\
\hline 67 & Barra do Bugres & $-0,342$ & $-0,767$ & 0,057 & 1,576 & 1,178 & 0,074 & 51,583 \\
\hline 68 & Nova Brasilândia & 0,442 & $-0,499$ & 0,673 & $-1,796$ & 0,893 & 0,070 & 51,449 \\
\hline 69 & Colíder & $-0,195$ & 0,085 & 1,995 & $-1,113$ & $-0,532$ & 0,070 & 51,428 \\
\hline 70 & São José do Xingu & 0,669 & $-0,719$ & $-0,100$ & $-0,485$ & 0,062 & 0,066 & 51,287 \\
\hline 71 & Itaúba & 0,390 & $-0,509$ & $-0,233$ & $-0,366$ & 0,771 & 0,066 & 51,286 \\
\hline 72 & Matupá & 0,403 & $-0,590$ & 0,519 & $-1,332$ & 0,686 & 0,048 & 50,599 \\
\hline 73 & Santo Afonso & 0,719 & $-0,999$ & 0,593 & $-0,464$ & $-1,021$ & 0,032 & 49,949 \\
\hline 74 & Gaúcha do Norte & 0,461 & $-0,681$ & $-0,515$ & 0,111 & 0,276 & 0,021 & 49,529 \\
\hline 75 & Canabrava do Norte & 0,319 & $-0,427$ & 0,500 & $-0,701$ & $-0,231$ & 0,018 & 49,414 \\
\hline 76 & Tabaporã & 0,716 & $-0,219$ & $-1,069$ & 0,269 & $-0,943$ & $-0,006$ & 48,483 \\
\hline 77 & Alto Boa Vista & 0,483 & $-0,739$ & 0,241 & $-1,189$ & 0,384 & $-0,010$ & 48,339 \\
\hline 78 & Nova Santa Helena & $-0,015$ & $-0,267$ & 0,139 & $-0,377$ & 0,545 & $-0,017$ & 48,036 \\
\hline 79 & Ribeirão Cascalheira & 0,370 & $-0,808$ & $-0,465$ & $-0,704$ & 1,234 & $-0,027$ & 47,677 \\
\hline 80 & Nova Maringá & 0,451 & $-0,268$ & $-0,669$ & $-0,542$ & 0,214 & $-0,027$ & 47,665 \\
\hline 81 & Nova Lacerda & 0,038 & $-0,159$ & $-0,677$ & $-0,529$ & 1,428 & $-0,034$ & 47,385 \\
\hline 82 & $\begin{array}{c}\text { Novo Horizonte do } \\
\text { Norte }\end{array}$ & $-0,453$ & 0,198 & 1,754 & $-1,226$ & $-0,234$ & $-0,035$ & 47,338 \\
\hline 83 & São José do Povo & $-0,505$ & $-0,862$ & 1,551 & 0,681 & $-0,270$ & $-0,038$ & 47,252 \\
\hline 84 & Porto Alegre do Norte & 0,649 & $-0,945$ & $-0,015$ & $-0,715$ & $-0,337$ & $-0,044$ & 46,984 \\
\hline 85 & Barra do Garças & $-0,168$ & $-0,876$ & 0,102 & 0,590 & 0,760 & $-0,045$ & 46,973 \\
\hline 86 & Santo Antônio do Leste & 0,982 & $-0,193$ & $-1,723$ & 0,032 & $-1,019$ & $-0,045$ & 46,973 \\
\hline
\end{tabular}


(Continua)

\begin{tabular}{|c|c|c|c|c|c|c|c|c|}
\hline Posição & Municípios & $\mathrm{F} 1$ & $\mathrm{~F} 2$ & $\mathrm{~F} 3$ & $\mathrm{~F} 4$ & F5 & IBD & IDR \\
\hline 87 & Marcelândia & 0,705 & $-0,577$ & $-0,420$ & $-2,059$ & 1,003 & $-0,046$ & 46,931 \\
\hline 88 & Santa Rita do Trivelato & 0,737 & 0,789 & $-2,242$ & $-0,084$ & $-0,852$ & $-0,050$ & 46,762 \\
\hline 89 & Nova Olímpia & $-1,316$ & $-0,059$ & 0,190 & 1,143 & 2,581 & $-0,063$ & 46,260 \\
\hline 90 & São Pedro da Cipa & $-0,403$ & $-0,643$ & $-0,059$ & 1,436 & 0,272 & $-0,070$ & 45,977 \\
\hline 91 & Conquista D'Oeste & $-0,042$ & $-0,255$ & $-0,054$ & $-0,444$ & 0,422 & $-0,082$ & 45,524 \\
\hline 92 & Bom Jesus do Araguaia & 0,786 & $-0,142$ & $-1,626$ & $-0,699$ & $-0,148$ & $-0,094$ & 45,058 \\
\hline 93 & Nova Nazaré & 0,180 & $-0,628$ & $-0,581$ & $-0,484$ & 0,681 & $-0,125$ & 43,838 \\
\hline 94 & Paranaíta & $-1,029$ & 0,532 & 1,498 & $-1,107$ & 0,582 & $-0,141$ & 43,209 \\
\hline 95 & Peixoto de Azeve & $-0,249$ & $-0,205$ & 0,090 & $-0,742$ & 0,668 & $-0,142$ & 43,175 \\
\hline 96 & Feliz Natal & 0,044 & $-0,276$ & $-1,138$ & $-0,353$ & 1,044 & $-0,152$ & 42,784 \\
\hline 97 & Jangada & $-0,575$ & $-0,198$ & 0,347 & 0,415 & 0,016 & $-0,153$ & 42,773 \\
\hline 98 & Guarantã do Norte & 0,510 & $-0,759$ & $-0,040$ & $-1,899$ & 0,261 & $-0,157$ & 42,596 \\
\hline 99 & Porto Esperidião & $-0,688$ & $-0,289$ & 1,076 & 0,334 & $-0,526$ & $-0,163$ & 42,364 \\
\hline 100 & Rio Branco & $-0,834$ & 0,163 & 1,491 & 0,287 & $-1,291$ & $-0,164$ & 42,342 \\
\hline 101 & Nova Monte Verde & $-0,434$ & $-0,098$ & 1,162 & $-1,425$ & 0,098 & $-0,170$ & 42,105 \\
\hline 102 & Curvelândia & $-0,892$ & $-0,759$ & $-0,194$ & 1,953 & 0,599 & $-0,206$ & 40,694 \\
\hline 103 & Cáceres & $-0,586$ & $-0,207$ & 0,331 & 0,001 & 0,083 & $-0,208$ & 40,627 \\
\hline 104 & Carlinda & $-1,218$ & $-0,012$ & 1,552 & $-0,024$ & 0,129 & $-0,218$ & 40,245 \\
\hline 105 & $\begin{array}{c}\text { Vila Bela da Santíssima } \\
\text { Trindade }\end{array}$ & 0,396 & $-0,614$ & $-0,411$ & $-0,152$ & $-1,548$ & $-0,219$ & 40,189 \\
\hline 106 & União do Sul & $-0,021$ & $-0,252$ & $-0,910$ & $-1,513$ & 1,589 & $-0,224$ & 39,983 \\
\hline 107 & Juara & $-0,406$ & 0,081 & 0,893 & $-1,599$ & $-0,193$ & $-0,228$ & 39,835 \\
\hline 108 & Rosário Oeste & $-0,901$ & $-0,344$ & $-0,329$ & 0,661 & 1,365 & $-0,239$ & 39,432 \\
\hline 109 & Denise & $-1,184$ & $-0,336$ & $-0,582$ & 1,434 & 1,771 & $-0,247$ & 39,117 \\
\hline 110 & Santa Terezinha & $-0,036$ & $-0,633$ & $-0,348$ & $-0,455$ & $-0,443$ & $-0,299$ & 37,081 \\
\hline 111 & Porto Estrela & $-0,545$ & $-0,867$ & $-0,532$ & 1,387 & $-0,732$ & $-0,370$ & 34,311 \\
\hline 112 & Santa Cruz do Xingu & 0,406 & $-0,827$ & $-1,127$ & $-1,269$ & $-0,430$ & $-0,393$ & 33,412 \\
\hline 113 & Apiacás & $-0,816$ & 0,399 & 0,324 & $-0,879$ & $-0,711$ & $-0,398$ & 33,227 \\
\hline 114 & Confresa & $-1,508$ & $-0,341$ & 0,431 & 0,522 & 1,088 & $-0,403$ & 33,014 \\
\hline 115 & Novo Santo Antônio & $-0,829$ & $-0,573$ & 0,531 & $-1,266$ & 0,525 & $-0,453$ & 31,086 \\
\hline 116 & Cocalinho & $-0,324$ & $-0,487$ & $-1,032$ & $-1,352$ & 0,864 & $-0,472$ & 30,347 \\
\hline 117 & Serra Nova Dourada & 0,125 & $-0,784$ & $-0,925$ & $-1,320$ & $-0,726$ & $-0,505$ & 29,071 \\
\hline 118 & Reserva do Cabaçal & $-1,212$ & 0,475 & $-0,248$ & 1,123 & $-1,952$ & $-0,522$ & 28,408 \\
\hline
\end{tabular}


(Conclusão)

\begin{tabular}{|c|c|c|c|c|c|c|c|c|}
\hline Posição & Municípios & $\mathrm{F} 1$ & $\mathrm{~F} 2$ & F3 & $\mathrm{F} 4$ & F5 & IBD & IDR \\
\hline 119 & Indiavaí & $-1,176$ & 0,639 & 0,900 & $-0,671$ & $-2,070$ & $-0,530$ & 28,084 \\
\hline 120 & Jauru & $-0,941$ & 0,178 & 0,442 & $-0,399$ & $-2,231$ & $-0,580$ & 26,141 \\
\hline 121 & Salto do Céu & $-1,985$ & 0,436 & 0,878 & 0,871 & $-1,088$ & $-0,583$ & 26,023 \\
\hline 122 & Nova Bandeirantes & $-0,805$ & 0,090 & $-0,269$ & $-1,812$ & 0,038 & $-0,587$ & 25,891 \\
\hline 123 & Araguainha & $-0,454$ & $-1,308$ & $-0,511$ & 0,111 & $-0,849$ & $-0,590$ & 25,757 \\
\hline 124 & Juína & $-1,202$ & 0,729 & 0,242 & $-1,002$ & $-1,291$ & $-0,590$ & 25,739 \\
\hline 125 & Campinápolis & $-1,922$ & 0,067 & $-0,232$ & 0,370 & 1,174 & $-0,619$ & 24,622 \\
\hline 126 & Ponte Branca & $-0,544$ & $-0,722$ & $-0,568$ & $-0,191$ & $-1,286$ & $-0,619$ & 24,610 \\
\hline 127 & Castanheira & $-0,851$ & $-0,453$ & 0,189 & $-0,916$ & $-1,029$ & $-0,631$ & 24,166 \\
\hline 128 & Poconé & $-1,923$ & $-0,055$ & $-0,459$ & 0,626 & 0,746 & $-0,696$ & 21,641 \\
\hline 129 & Cotriguaçu & $-1,363$ & 0,536 & $-0,047$ & $-1,866$ & $-0,781$ & $-0,794$ & 17,829 \\
\hline 130 & Várzea Grande & $-2,552$ & 0,266 & $-0,745$ & 0,810 & 1,540 & $-0,825$ & 16,617 \\
\hline 131 & Juruena & $-1,484$ & 0,116 & $-0,426$ & $-1,730$ & 0,296 & $-0,842$ & 15,962 \\
\hline 132 & Cuiabá & $-2,786$ & 0,183 & $-0,771$ & 0,887 & 1,649 & $-0,916$ & 13,058 \\
\hline 133 & Araguaiana & $-2,516$ & 0,028 & $-0,567$ & 0,861 & 0,233 & $-0,966$ & 11,108 \\
\hline 134 & Luciara & $-0,785$ & $-0,800$ & $-1,472$ & $-2,357$ & 0,014 & $-1,018$ & 9,086 \\
\hline 135 & Pontal do Araguaia & $-2,255$ & $-0,181$ & $-1,417$ & 0,803 & 0,395 & $-1,033$ & 8,534 \\
\hline 136 & Rondolândia & $-1,572$ & 0,400 & $-0,360$ & $-0,036$ & $-3,541$ & $-1,034$ & 8,497 \\
\hline 137 & Colniza & $-2,128$ & 0,231 & $-1,025$ & $-0,054$ & $-0,521$ & $-1,057$ & 7,575 \\
\hline 138 & $\begin{array}{c}\text { Nossa Senhora do } \\
\text { Livramento }\end{array}$ & $-2,084$ & $-0,401$ & $-1,496$ & 1,129 & $-0,999$ & $-1,134$ & 4,570 \\
\hline 139 & Barão de Melgaço & $-1,986$ & $-0,157$ & $-1,430$ & 0,978 & $-2,078$ & $-1,183$ & 2,667 \\
\hline 140 & Acorizal & $-2,877$ & 0,009 & $-1,112$ & 0,940 & $-0,158$ & $-1,243$ & 0,359 \\
\hline 141 & Aripuanã & $-1,801$ & 0,385 & $-1,259$ & $-1,349$ & $-1,797$ & $-1,253$ & 0,000 \\
\hline
\end{tabular}

Fonte: Resultado da pesquisa, 2012. 